\title{
PLANEJAMENTO E CONTROLE DA MANUTENÇÃO APLICADOS AO PROCESSO DE BENEFICIAMENTO DE ARROZ
}

\author{
Delânio da Silva Oliveira (Universidade Federal do Ceará) delaniosilva@gmail.com \\ Iany de Assis Maia (Universidade Federal do Ceará) ianymaia35@gmail.com \\ Lara Fernanda Cavalcante Nery (Universidade Federal do Ceará) larafnery @ gmailcom \\ Mágda Ferreira Maia Torre (Universidade Federal do Ceará) magdamaia23@ gmail.com \\ Daiane Oliveira da Costa (Universidade Federal do Ceará) daianecosta@ufc.br
}

\section{Resumo}

Sabe-se que no ano de 2015 a região do baixo Jaguaribe correspondia a 75,45\% (IBGE, 2018) da produção de arroz no Ceará. Assim, percebe-se a concorrência na região, onde surge a necessidade de uma produção otimizada por meio da eficiência de seus ativos. Com isso, o objetivo deste estudo é aplicar conceitos de planejamento e controle da manutenção em uma empresa beneficiadora de arroz para o aumento de disponibilidade do maquinário na indústria. Primeiramente houveram visitas e entrevistas ao local para conhecer o processo produtivo da empresa, para que fosse possível identificar problemas que poderiam ser solucionados com as técnicas e práticas de manutenção. Propondo a aplicação de conceitos como, manutenção preventiva, manutenção autônoma, tagueamento, planos de manutenção padronizados, assim, buscando a melhoria contínua das operações na empresa estudada.

Palavras-Chaves: Beneficiamento de arroz. Disponibilidade. Falhas. Manutenção. Melhorias.

\section{Introdução}

O arroz é um alimento que se destaca entre os grãos por estar vinculado à cultura de vários povos, além do seu valor nutricional. A história desse grão no Brasil é incerta, porém, entendese que o uso começou com os povos indígenas e posteriormente virou tradição na alimentação dos brasileiros.

O Brasil, como um país emergente, tem a maior parte de sua economia sustentada pela pecuária e produção agrícola, as quais são praticadas por todo território nacional. De acordo com a Companhia Nacional de Abastecimento - CONAB (2019), foi previsto que haveria um aumento de 1,8\% da safra de grãos de 2018/19 em comparação ao ano anterior. No entanto, foi apontado um decréscimo na produção de arroz de $12,2 \%$, com isso, espera-se que os preços de vendas tenham uma maior valorização, por tratar-se de um commodity, caracterizando assim uma oportunidade para as indústrias de beneficiamento de arroz aumentarem seus lucros. 
Para que chegue até os consumidores finais, o grão passa por processos industriais para o seu tratamento e limpeza, a fim de garantir a qualidade do produto. Dentre estes processos estão a pré-limpeza, secagem, armazenamento, beneficiamento, seleção e empacotamento (CASTRO et al., 1999). Por tratar-se do ramo alimentício, cuja produção se dá para subsistência, é necessário que as indústrias de beneficiamento assegurem a disponibilidade de seus recursos e equipamentos, de forma que consigam atender ao mercado.

Dessa forma, a manutenção dos equipamentos é uma das vias que as organizações utilizam para evitar falhas e cuidar das suas instalações físicas. Quando realizada de forma eficaz, a manutenção garante maior segurança, maior confiabilidade e melhor qualidade, visto que um equipamento mal conservado possui maior probabilidade de apresentar defeitos. Tudo isso implicará na redução de custos operacionais e em uma maior vida útil da tecnologia de processos, entregando maior "valor final”. (SLACK; CHAMBERS; JOHNSTON, 2018).

O presente trabalho foi realizado em uma empresa de beneficiamento de arroz localizada em uma cidade do Baixo Jaguaribe, região do interior do Ceará, a qual realiza a distribuição de duas marcas deste produto, uma com maior qualidade, sendo esta a principal, e outra a preço popular.

De acordo com Instituto Brasileiro de Geografia e Estatística - IBGE (2018), em 2015, a região do Baixo Jaguaribe era responsável por $75,45 \%$ da quantidade produzida de arroz no estado cearense, rendendo cerca de 15.145.000 reais em um ano. Com base nestes dados, percebe-se que a cultura de arroz é muito forte na região, justificando assim a importância de estudos nas indústrias desse segmento, para tornar a sua produtividade mais eficiente e obter vantagem competitiva sobre os demais concorrentes.

No estudo foi realizado um acompanhamento em uma empresa do segmento de grãos, onde não existe um setor de manutenção, logo não apresenta funcionários destinados a essas atividades, sendo estas realizadas pelos proprietários quanto tratam-se de atividades simples. Já as mais complexas, que exigem maior conhecimento técnico, são terceirizadas. Em ambos os casos, a manutenção realizada é corretiva, o que consequentemente provoca grandes paradas no processo, além da alta quantidade de produtos defeituosos dado o mau funcionamento das máquinas. Para eliminar esses desperdícios, é necessário ter uma gestão eficaz da manutenção, para isso faz-se o Planejamento e Controle da Produção (PCM), pois de acordo com Marques (2014), um bom planejamento oferece segurança ao mantenedor para executar suas tarefas sem interrupções por falta de materiais ou informações. 
Nesse contexto, o objetivo do trabalho consiste na proposição de práticas e atividades referentes ao planejamento e controle da manutenção, a fim de garantir a disponibilidade e confiabilidade dos equipamentos da empresa de beneficiamento de arroz estudada.

\section{Referencial teórico}

\subsection{Manutenção}

A manutenção, de acordo com a NBR 5462, é definida como "combinação de todas as ações técnicas e administrativas, incluindo as de supervisão, destinadas a manter ou recolocar um item em um estado no qual possa desempenhar uma função requerida" (ASSOCIAÇÃO BRASILEIRA DE NORMAS TÉCNICAS, 1994, p. 6), ou seja, é caracterizada pelo conjunto de atividades técnicas, seja de reparo ou de acompanhamento, que possuem o objetivo de manter o funcionamento padrão de máquinas e equipamentos.

As primeiras atividades de manutenção buscavam apenas corrigir falhas nos equipamentos, a fim de garantir sua total finalidade. Nos últimos anos, essas tarefas deixaram de ser somente corretivas, devido ao surgimento de outras técnicas de manutenção como preditiva, preventivas e autônoma. Essas atividades, servem para evitar o mau desempenho dos ativos das instalações da indústria, causadas por falhas devido ao tempo de uso, vida útil ou manuseio inadequado, sendo assim, a realização dessas atividades visam manter a eficiência dos sistemas (XENOS, 2014).

\subsection{Tipos de manutenção}

De acordo com Xenos (2014), existem diversos métodos de manutenção e diferentes maneiras de classificá-los, detalhados no quadro 1. O autor afirma que cada tipo tem seu bônus e ônus, logo, a manutenção escolhida pela organização deve ser a combinação daquelas que melhor se adequa à determinada situação, levando sempre em consideração os custos da manutenção e as perdas no caso de ocorrência de falhas.

Quadro 1 - Tipos de manutenção

\begin{tabular}{|c|l|}
\hline TIPO & \multicolumn{3}{|c}{ CONCEITO } \\
\hline $\begin{array}{c}\text { Manutenção } \\
\text { corretiva }\end{array}$ & $\begin{array}{l}\text { A falha é corrigida somente depois que ocorre. Os custos de } \\
\text { manutenção são mais baratos, mas podem causar perdas pela } \\
\text { interrupção da produção. }\end{array}$ \\
\hline
\end{tabular}




\begin{tabular}{|c|l|}
\hline $\begin{array}{c}\text { Manutenção } \\
\text { preventiva }\end{array}$ & $\begin{array}{l}\text { São feitas tarefas sistemáticas, como inspeção, reparos e trocas de } \\
\text { peças programadas, a qual são realizadas a fim de evitar que aconteçam } \\
\text { as falhas, caso estas sejam cumpridas. Os custos de manutenção são } \\
\text { mais caros se comparado com a corretiva, porém, a incidência de falhas } \\
\text { e interrupções inesperadas na produção é pequena }\end{array}$ \\
\hline $\begin{array}{c}\text { Manutenção } \\
\text { preditiva }\end{array}$ & $\begin{array}{l}\text { Euando os componentes estão próximos de seu limite de vida, permitindo } \\
\text { otimizar o ato da manutenção, de forma que só acontece o reparo, seja } \\
\text { preventiva ou corretiva, quando é identificado uma queda de } \\
\text { desempenho e, geralmente, possuem custos mais baixos que a a } \\
\text { preventiva. }\end{array}$ \\
\hline
\end{tabular}

Fonte: Adaptado de XENOS (2014)

\subsection{Planejamento e Controle da Manutenção}

O PCM, de acordo com Viana (2014), é de suma importância para a saúde da empresa e tem como objetivo organizar e melhorar a manutenção. O autor afirma que o PCM é um órgão de suporte à manutenção, estando diretamente ligado à alta gerência da empresa. Da mesma forma, Carvalho et al. (2009) atribuem ao setor de PCM, a administração das informações e análises de resultados, para auxiliar a gerência nas tomadas de decisões estratégicas relativas à gestão de ativos e de produção, assim como na definição do cronograma de paradas do maquinário.

Quanto à elaboração de um plano de manutenção eficiente e devidamente organizado, por se tratar de uma atividade complexa, Viana (2014) a divide em quatro etapas principais, que possuem atividades e requisitos específicos, sendo elas:

- Organização da manutenção: consiste na identificação e codificação dos ativos e dos processos de manutenção;

- Cadastros necessários para o PCM: consiste na reunião dos cadastros e características necessárias para o ato da manutenção;

- Planos de manutenção: identificar a melhor abordagem e política de manutenção a serem implantadas;

- Planejamento e Programação da Manutenção: definir o que é, quem será o responsável, quando irá ser iniciado, como será realizado, porquê realizar e quanto custa o plano de manutenção.

\subsection{Plano de manutenção}


XENOS (2014) compara o plano de manutenção com um calendário e comenta que a necessidade de manutenção preventiva nos equipamentos é um dos principais fatores que levam as empresas a elaborarem um plano de manutenção. Esse planejamento deve listar todas as atividades preventivas essenciais para que falhas sejam menos recorrentes no sistema e garantir o funcionamento padrão das máquinas. Com isso, é necessário que haja um conhecimento abrangente das necessidades da manutenção.

O plano de manutenção deve contar também com a execução de atividades simples que colaboram para a durabilidade dos equipamentos, que se resumem em uma manutenção autônoma, realizadas em intervalos de tempo menores ou quando os operadores perceberem a necessidade.

\subsection{Manutenção autônoma}

Manutenção autônoma é um dos pilares que complementa a manutenção produtiva total (TPM), que pode ser considerada como um conjunto de técnicas de manutenção que busca englobar todos os setores da produção para que haja uma economia com custos de manutenção. Esse pilar consiste em deixar o operário na responsabilidade de realizar as manutenções rotineiras e básicas, como limpeza do ambiente de trabalho, lubrificação, inspeção e ajuste das máquinas, de formar que o enfoque das equipes de manutenção sejam voltados à realização de práticas mais complexas ( ZARREH et al. 2019).

Segundo Xenos (2014), apenas as atividades do departamento de manutenção são insuficientes para que seja possível usufruir do desempenho total dos equipamentos, portanto, é necessário que haja a implantação de atividades padrão que podem ser executadas pelos próprios operadores do chão de fábrica, como limpeza, lubrificação, reaperto e inspeção, além de detectar pequenas anomalias, havendo a possibilidade de tratá-las antes que ocorra a falha, assim, ajudam a prolongar a vida útil dos equipamentos (FOGLIATTO; RIBEIRO, 2009). Logo, é importante sempre a realização investigações de novas falha, de forma a corrigi-las e preveni-las através de um bom planejamento, para utilização máxima da disponibilidade dos ativos físico.

\subsection{Ciclo PDCA}

Quando deseja-se analisar e solucionar problemas, é necessário possuir um controle de todas as etapas do projeto, para isso a gestão da qualidade disponibiliza diversas ferramentas, uma delas é o ciclo PDCA, que de acordo com Deming (1990), é uma ferramenta de controle da qualidade que auxilia na melhoria contínua dos processos e engloba quatro etapas: 
- Plan (planejar): consiste no estabelecimento de metas, formulação de ideias e criação de planos de ação para a execução de determinado processo.

- Do (executar): são feitos treinamentos e execuções das operações planejadas.

- Check (checar): acompanhamento das atividades para análise dos padrões e verificação do atendimento dos requisitos.

- Action (agir): elaboração de novos planos para a melhoria dos processos que não atenderam os requisitos com o intuito de melhor o desempenho das operações.

Esta ferramenta consiste em um ciclo contínuo que busca analisar sempre possibilidades de melhorias no sistema.

\section{Metodologia}

\subsection{Caracterização da pesquisa}

O procedimento do trabalho se caracteriza como estudo de caso, uma vez que investiga as situações apresentadas de forma a compreender e descrever suas relações. Quanto à natureza, a pesquisa é classificada como aplicada, pois a busca pelo conhecimento visa a posterior realização de aplicações práticas, de acordo com métodos estruturados (FACHIN, 2006).

A pesquisa se dá através da abordagem metodológica do tipo qualitativa, pois as análises foram feitas de forma subjetiva pelos autores, sem nenhum dado numérico, para elaboração dos resultados (GIL, 2002). E a fim de auxiliar no desenvolvimento do trabalho, foram feitas pesquisas bibliográficas, em fontes como livros, revistas, artigos, normas técnicas, sobre o setor alimentício de beneficiamento de arroz, bem como técnicas e práticas para um bom planejamento e controle da manutenção.

E para alcance do objetivo, de acordo com Gil (2002), a pesquisa é de caráter exploratório e descritivo, de modo que foram feitas observações sistêmicas sobre a situação, para melhor compreensão, assim interpretá-lo e elaborar conclusões da melhor forma. Na figura 3, pode-se visualizar melhor a caracterização da pesquisa.

Figura 3 - Caracterização da pesquisa 


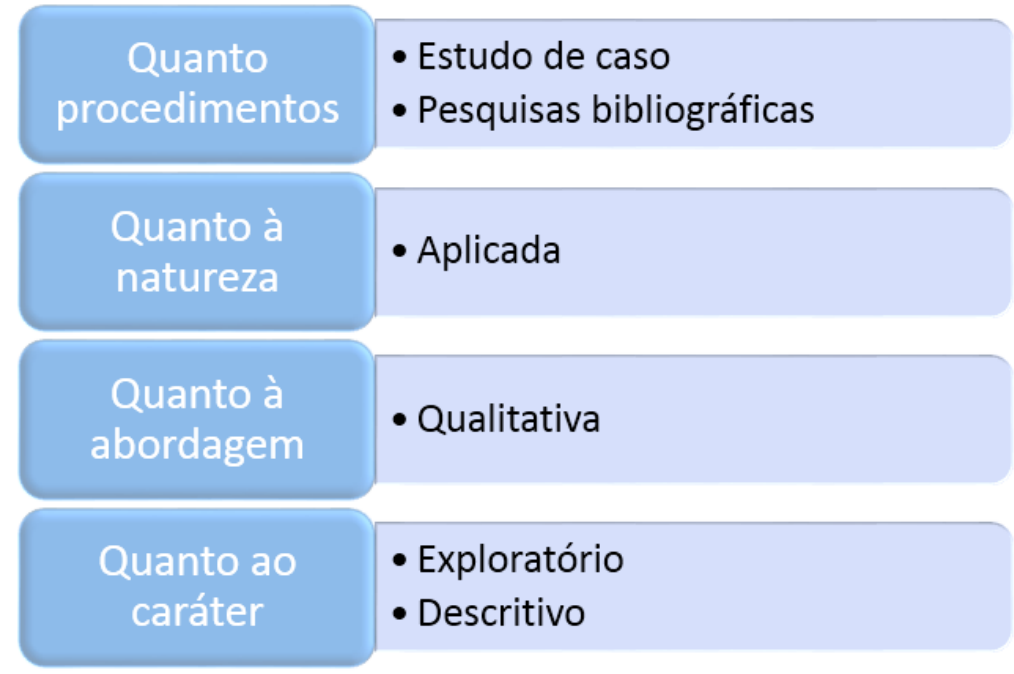

Fonte: Autores (2019)

\subsection{Métodos e procedimentos}

Inicialmente realizou-se uma visita no dia 09 de maio para entender melhor o processo produtivo da indústria beneficiadora de arroz, onde foi feito o acompanhamento de todo deste, analisando os tempos de processamento, de ciclo e de parada. No dia 21 de junho ocorreu uma segunda visita, onde se deu a realização de uma entrevista não estruturada com os proprietários da empresa. O objetivo consistiu em fazer um levantamento do problemas mais recorrentes, bem como dos equipamentos que apresentam o maior índice de falha e a frequência com que estas ocorrem.

Em seguida, iniciou-se o estudo bibliográfico para servir de embasamento à aplicação de técnicas e ferramentas para a implantação do planejamento e controle da manutenção, onde foram apresentados e discutidos sobre sua importância nos resultados do estudo, mostrando, também, sua contribuição para um bom desempenho dos processos e aumento da qualidade dos produtos.

\subsection{Caracterização da empresa}

O estudo de caso realizou-se em uma empresa privada do ramo industrial de grãos, na região do Baixo Vale do Jaguaribe, no estado do Ceará. O processo de produção estudado é o beneficiamento do arroz, que apresenta atualmente um quadro de funcionários formado por dois sócios proprietários e três colaboradores.

Em relação ao processo de transformação da empresa, apresentado na Figura 1, tem-se com inputs os funcionários, os equipamentos/máquinas, os materiais e a matéria-prima, que são os grãos de arroz. Tratando de outputs, têm-se os produtos finais, que são os dois tipos de arroz beneficiados: o tipo 1, que é o produto principal e apresenta uma maior qualidade, sendo 
responsável por $80 \%$ da produção; e o tipo 2, que é o produto com qualidade mais baixa, possuindo um preço comercial menor, de modo que representa $20 \%$ do total produzido.

Figura 1 - Processo de transformação

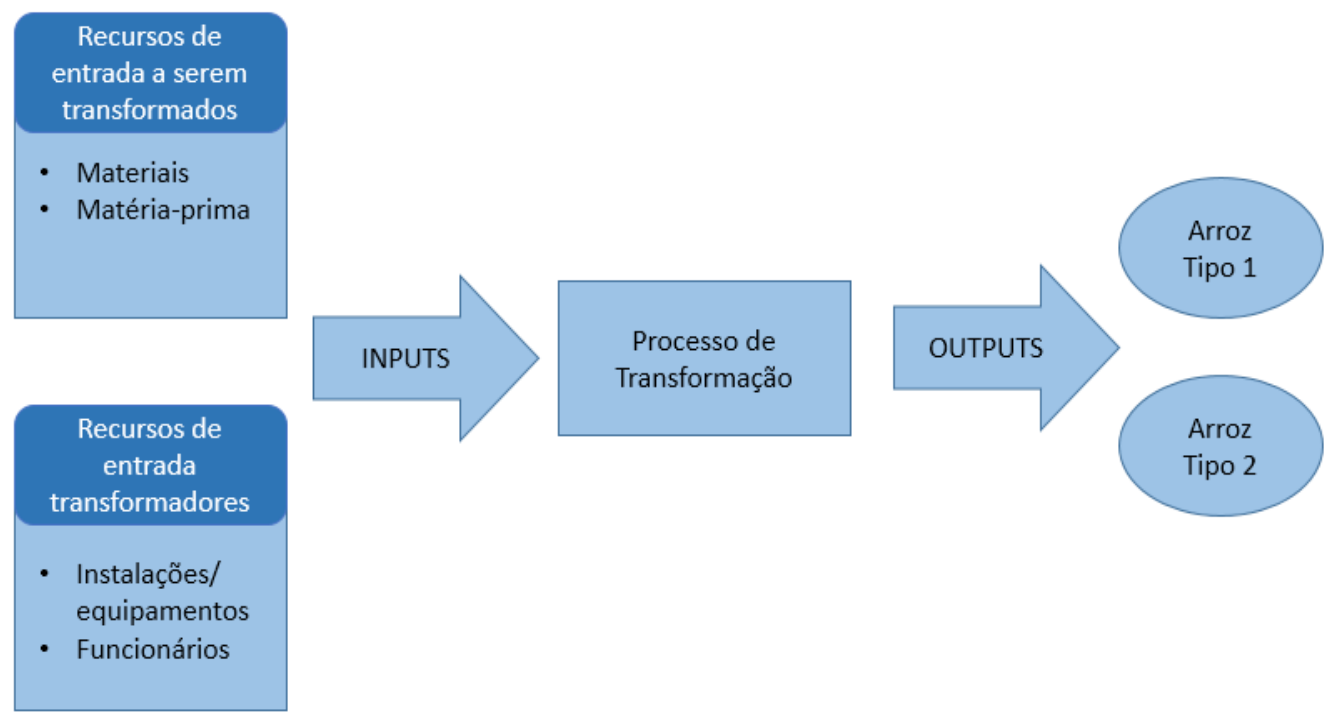

Fonte: Autores (2019)

Visando um melhor entendimento do processo de beneficiamento do arroz, desenhou-se um fluxograma do processo produtivo, que pode ser visualizado na Figura 2.

Figura 2 - Fluxograma do processo produtivo

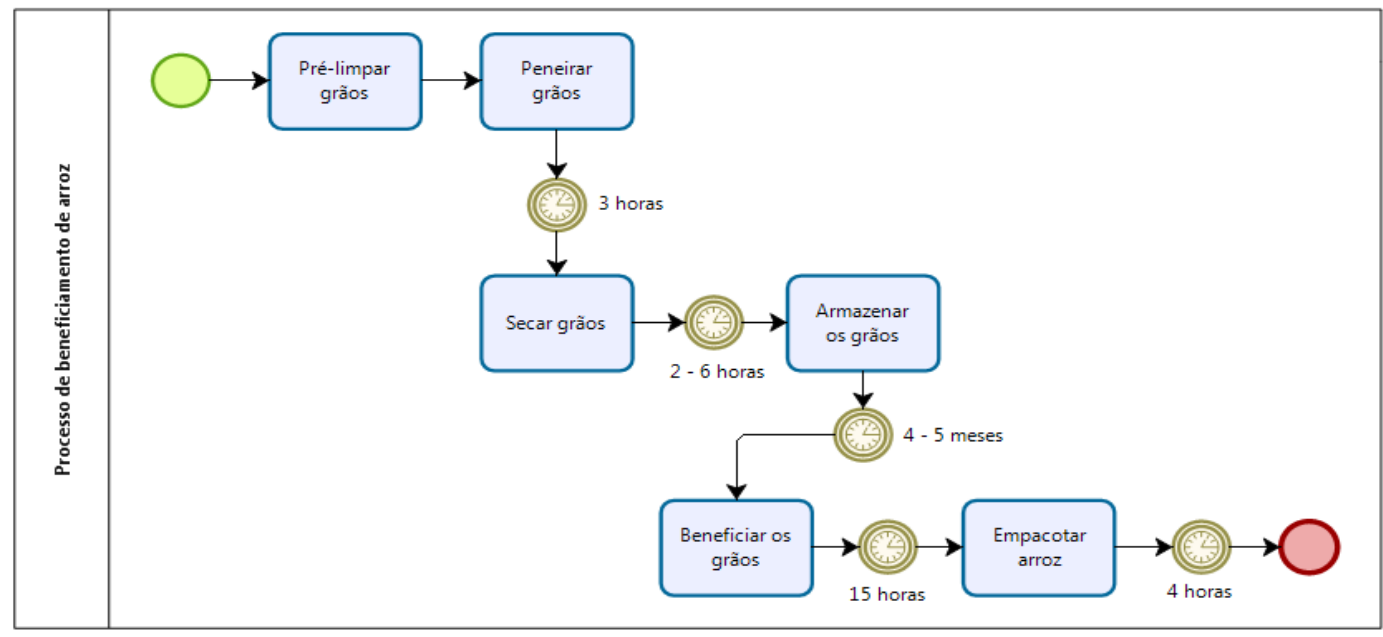

Fonte: Autores (2019)

A descrição das atividades acima são apresentadas no Quadro 2.

Quadro 2 - Descrição das etapas 


\begin{tabular}{|c|l|}
\hline ETAPAS & \multicolumn{1}{|c|}{ ATIVIDADES } \\
\hline Pré-limpeza & São retiradas impurezas superficiais para iniciar o processo. \\
\hline Peneiração & Retirada de materiais pequenos que não fazem parte do arroz. \\
\hline Secagem & $\begin{array}{l}\text { Os grãos chegam com 25\% a 30\% de umidade, a secagem } \\
\text { reduz para 13\% de umidade. }\end{array}$ \\
\hline Armazenamento & $\begin{array}{l}\text { Armazena-se o arroz, ainda com casca, com o intuito de } \\
\text { proporcionar a qualidade do mesmo. }\end{array}$ \\
\hline Beneficiamento & $\begin{array}{l}\text { Máquina que ocorre os seguintes processos: limpeza, } \\
\text { descascamento, seleção, brunição (branqueamento) e } \\
\text { polimento. O arroz passa por máquinas que separam os grãos } \\
\text { inteiros, de valor comercial mais alto, dos que possuem valor } \\
\text { comercial mais baixo e dos demais subprodutos que serão } \\
\text { utilizados para ração animal (casca e pó de arroz). }\end{array}$ \\
\hline Expedição & $\begin{array}{l}\text { O arroz é embalado em pacotes de 1 kg e acomodados em } \\
\text { fardo de 30 kg. } \\
\text { Expacotidos. são estocados para posteriormente serem }\end{array}$ \\
\hline
\end{tabular}

Fonte: Autores (2019)

\section{Propostas para implantação do PCM}

Dando início à implantação do Plano de Manutenção, a primeira tarefa a ser feita é denominar a equipe que ficará responsável por registrar ocorrências, liberar as ordens de serviço e realizar a manutenção. Dessa forma, levando em consideração a empresa de estudo, por possuir poucos colaboradores, toda a equipe deve ser preparada, incluindo os proprietários.

\subsection{Levantamento dos ativos}

Após a determinação da equipe, é desejável realizar o inventário dos ativos presentes na empresa, ou seja, identificar os equipamentos utilizados para a transformação dos inputs em outputs. No quadro a seguir está descrito os ativos da beneficiadora assim como sua marca e localização.

Quadro 3 - Ativos da empresa de beneficiamento de arroz

\begin{tabular}{|c|c|c|}
\hline EQUIPAMENTO & MARCA & LOCALIZAÇÃO \\
\hline Secador e peneira & Zacarias & Área externa \\
\hline Beneficiar & Zacarias & Galpão \\
\hline Empacotar & Indumak & Expedição \\
\hline
\end{tabular}


Fonte: Autores (2019)

Além da identificação das máquinas existentes na indústria, é preciso fazer uma lista das peças (Quadro 4) que mais apresentam falha, ou necessitam ser trocados, de acordo com cada máquina. Vale ressaltar que esses dados foram obtidos através da entrevista com colaboradores e proprietários, visto que a empresa não dispõe de um histórico de falhas.

Quadro 4 - Peças que compõem cada máquina

\begin{tabular}{|c|c|}
\hline MÁQUINA & PEÇAS \\
\hline Secador e peneira & Peneira, canecas, rolamentos, correia e rosca transportadora. \\
\hline Beneficiamento & Canecas, rolamentos e correia. \\
\hline Empacotar & Canecas, rolamentos e correia. \\
\hline
\end{tabular}

Fonte: Autores (2019)

\subsection{Tagueamento}

Feito o levantamento de equipamentos optou-se por fazer um tagueamento, o qual consiste em uma identificação única e simples para uma rápida identificação dos equipamentos que necessitam de reparo, dos itens que precisam ser trocados ou das máquinas que irão passar por manutenção em determinado período. Abaixo segue um exemplo de tag sugerido e a identificação de cada parte:

Figura 4 - Tag's para os ativos

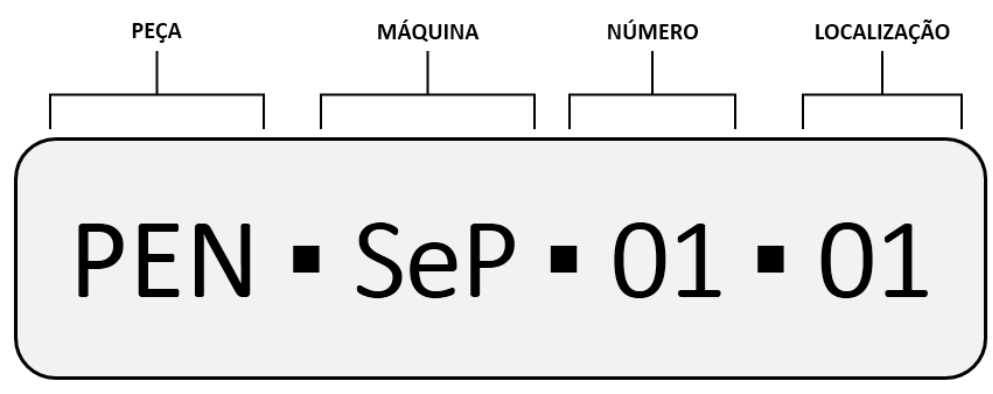

Fonte: Autores (2019)

Quadro 5 - Identificação da tag

\begin{tabular}{|c|c|c|c|}
\hline SIGLA & SIGNIFICADO & SIGLA & SIGNIFICADO \\
\hline PEN & Peneira & ROL & Rolamentos \\
\hline COR & Correia & SeP & Secador e Peneira \\
\hline CAN & Caneca & BEM & Beneficiadora \\
\hline ROT & Rosca transportadora & EMP & Empacotadora \\
\hline
\end{tabular}

Fonte: Autores (2019)

Onde o primeiro espaço da tag é destinado a identificar as peças que sofrem reparos, o segundo serve para identificar as máquinas que estão instaladas na indústria, o terceiro, chamando de número, é a numeração da máquina, caso exista mais de uma, e o último espaço é para localização do setor onde a máquina se situa na planta. 


\subsection{Levantamento das falhas}

Com o levantamento de todos os equipamentos que fazem parte do beneficiamento de arroz, é interessante analisar quais os principais defeitos que cada um apresenta e com que frequência pode ser observado esses defeitos. Afinal, os equipamentos devem ser utilizados na sua maior disponibilidade, para isso é necessário existir confiabilidade em relação ao equipamento, de forma que estará em condições de ser utilizado quando for necessário. De acordo com os proprietários as principais ocorrências, são:

- Secador: peneira rasgada, rolamento quebrado e trincado, rosca transportadora e canecas corroída, correia frouxa e estourada;

- Beneficiador: Canecas corroída, turbina entupida pelas roscas transportadoras desgastadas, correia frouxa e estourada, rolamento quebrado e trincado.

- Empacotadora: Correia frouxa e estourada, canecas desgastadas, rolamento quebrado e trincado, além de apresentar muito problema pneumático e elétricos nos sensores que fazem a leitura para fechar as embalagens, neste caso também informou que as embalagens apresentam manchas que dificultam a leitura, ocasionando em mais erros.

E a taxa de falha que cada máquina apresenta é descrito no quadro abaixo:

Quadro 4 - Média da ocorrência de falhas de cada máquina

\begin{tabular}{|c|c|}
\hline MÁQUINA & TAXA DE FALHA \\
\hline Secador e peneira & 2 falhas por ano \\
\hline Beneficiar & 1 falha por mês \\
\hline Empacotar & 2 falhas por mês \\
\hline
\end{tabular}

Fonte: Autores (2019)

\subsection{Plano de manutenção}

De acordo com a análise do processo produtivo percebeu-se que a máquina de empacotamento possui um tempo de setup superior ao esperado devido a problemas frequentemente apresentados na mesma, que, coincidentemente, podem ser resultantes de uma má gestão, principalmente na parte da manutenção. Com isso, a fase de empacotamento seria classificada como gargalo da produção, sendo o foco do desenvolvimento do trabalho. Vale ressaltar que o processo anterior ao de empacotamento, beneficiamento do arroz, possui um tempo de processamento menor, gerando uma grande demanda nessa etapa, que por sua vez não está operando com eficiência. 
Dessa forma, para que seja alcançada uma maior confiabilidade de todas as máquinas, elas seguirão um plano de manutenção preventiva para evitar atrasos e principalmente desperdícios no processo. Com isso, para que exista uma confiança maior dos dados, também será sugerido que se aplique uma folha de verificação para cada ativo, com a finalidade de ter a data da manutenção corretiva e os motivos correspondentes a cada componente que falhou de cada máquina, através de uma folha de verificação, apresentada na figura a seguir.

Figura 5 - Folha de verificação para manutenção de cada máquina

\begin{tabular}{|l|l|}
\hline \multicolumn{2}{|c|}{ MANUTENÇÃO } \\
\hline IDENTIFICAÇÃO & \\
\hline & \\
\hline DATA DA MANUTENÇÃO & \\
\hline & \\
\hline & \\
\hline & \\
\hline & \\
\hline & \\
\hline & \\
\hline & \\
\hline & \\
\hline & \\
\hline & \\
\hline & \\
\hline
\end{tabular}

Fonte: Autores (2019)

Dessa forma, para facilitar e padronizar a manutenção das máquinas da indústria, a fim de reduzir os problemas causados pela má manutenção dos ativos, e trazer conforto e segurança, tanto para quem faz a manutenção, quanto para quem gerenciar, elaborou-se um modelo de ordem de serviço (OS), na figura 6, para ser aplicado pela equipe.

Figura 6 - Modelo de OS para ser aplicado para manutenção das máquinas 


\begin{tabular}{|c|c|c|}
\hline BENEFICIADORA DE ARROZ & ORDEM DE SERVIÇO & $\begin{array}{l}\text { Setor: } \\
\text { Data: } \\
\text { Equipamento: } \\
\text { Data da Revisão: } \\
\text { № da Revisão: }\end{array}$ \\
\hline \multicolumn{3}{|l|}{ TAREFA: } \\
\hline \multicolumn{3}{|l|}{ RESPONSÁVEL: } \\
\hline \multicolumn{3}{|l|}{ OBJETIVO DA TAREFA: } \\
\hline \multicolumn{3}{|l|}{ MATERIAS NECESSÁRIOS: } \\
\hline \multicolumn{3}{|l|}{ PASSOS CRÍTICOS: } \\
\hline \multicolumn{3}{|l|}{ CUIDADOS: } \\
\hline \multicolumn{3}{|l|}{ AÇÕES CORRETIVA: } \\
\hline ELABORADO POR: & \multicolumn{2}{|c|}{ APROVADO POR: } \\
\hline
\end{tabular}

Fonte: Autores (2019)

Dado o modelo da ordem de serviço, seria explicado o que significa cada campo que o compõe:

- Setor: será preenchido com o setor que será implementado e implantado a OS;

- Data: seria a de implantação, data manutenção;

- Equipamento: qual máquina/equipamento que será aplicada a OS;

- Data de Revisão: preenchido com a data da revisão, quando houver;

- No da Revisão: será inserido o número de edição a que se refere a revisão;

- Tarefa: coloca-se qual a atividade a ser executada;

- Responsável: a equipe, setor ou pessoa que executa a tarefa;

- Objetivo da Tarefa: resultados esperados com a realização da tarefa;

- Materiais Necessários: lista dos tipos de materiais e ferramentas necessárias para a execução da tarefa;

- Passos críticos: descrição detalhada do processo, de como executar a tarefa, ou seja, os passos a serem seguidos para a realização correta da atividade;

- Cuidados Especiais: onde são colocados os cuidados necessários, para que não ocorra erros durante a realização da tarefa;

- Ações corretivas: caso não ocorra tudo conforme a OS, é preenchido neste espaço o que o responsável deverá fazer; 
- Elaborado por: o autor da ordem de serviço;

- Aprovado por: quem da alta gerência aprovou a elaboração do formulário.

Após a utilização das folhas de verificação, com a aplicação de uma ferramenta da qualidade, o ciclo PDCA, a equipe de manutenção analisaria os dados coletados da máquina em embalar, por esta ser a que mais tem ocorrência de falhas, elaboraria um plano de manutenção preventiva para ser aplicado e, ainda, realizar um treinamento com os funcionários, de modo que eles possam manter as máquinas em pleno funcionamento.

A intenção é aplicar a manutenção autônoma além da preventiva, tornando os funcionários manutentores, os quais realizariam a limpeza das máquinas que operam, fariam acompanhamento do desempenho das mesmas, além de reparos simples, como lubrificação, de maneira a conservar o equipamento mantendo um alto nível de disponibilidade.

Posteriormente a aplicação do plano de manutenção, preventiva e autônoma combinadas, por meio das OS's deve-se analisar e conferir se houve melhoras no processo, como mais disponibilidade da máquina, redução dos custos e desperdícios de matéria-prima e tempo. Caso o objetivo não tenha sido alcançado, identifica-se os motivos, para se traçar um novo plano, senão, por ter resultados positivos, poderia ser aplicado o método em outros ativos da indústria, melhorando o processo como todo.

\section{Considerações finais}

É notório que o plano de manutenção é de suma importância para um bom andamento da produção, tendo em vista que o maquinário deve estar em disponibilidade sempre que necessário. Essa preocupação se multiplica quando se tem apenas um equipamento para cada função na linha de produção.

Levando em consideração o plano de manutenção preventiva sugerido, um pequeno reparo pode evitar maiores danos na máquina e por consequência seu índice de disponibilidade iria ser abaixo do esperado.

O trabalho apresentou dificuldades no que diz respeito, o levantamento de dados já que na empresa analisada não havia histórico de falhas e nem de manutenções. Para tal, foi sugerido o uso de folhas de verificação para começar a coleta de dados históricos de manutenção, para futuras aplicações.

Para trabalhos futuros se faz necessário a aplicação da Manutenção Centrada em Confiabilidade, para a máquina que se apresenta como o gargalo no processo, que no caso, é a 
empacotadora. Esse trabalho seria realizado através do desmembramento dos componentes do equipamento, suas principais falhas e o que ocasiona essas falhas.

\section{REFERÊNCIAS}

ASSOCIAÇÃO BRASILEIRA DE NORMAS TÉCINICAS. NBR 5462: Confiabilidade e Manutenabilidade, 1994.

CASTRO, E. da M. de: VIEIRA, N.R. de A.; RABELO, R.R.; SILVA, S.A. da. Qualidade de grãos em arroz. Santo Antônio de Goiás: Embrapa Arroz e Feijão, 1999. 30p.

CARVALHO, André Moreira de; GOMES, Geraldo Messias; BORGES, Márcio de Castro; FERREIRA JÚNIOR, Nilton Bráz. Implantação de sistema informatizado para planejamento e controle da manutenção - Empresa Vileflex. Universidade Vale do Rio Doce (UNIVALE) e Faculdade de Ciências Exatas e Tecnológicas (FAENG). Governador Valadares - MG, 2009.

Companhia Nacional de Abastecimento. Acompanhamento da safra brasileira de grao. Brasília. v.6, n.8,2019.

DEMING, William Edward. Qualidade: a revolução da administração. Rio de Janeiro: Marques-Saraiva, 1990.

FACHIN, Odília. Fundamentos da Metodologia. 5. ed. São Paulo: Saraiva, 2006. 209 p.

FOGLIATTO, Flávio Sanson; RIBEIRO, José Luis Duarte. Confiabilidade e Manutenção Industrial. Rio de Janeiro: Elsevier, 2009. 265 p

GIL, Antônio Carlos. Como elaborar projetos de pesquisa. 4. ed. São Paulo: Editora Atlas, 2002. 171 p.

INSTITUTO BRASILEIRO DE GEOGRAFIA E ESTATÍSTICA. Área plantada, área colhida, quantidade produzida, rendimento médio e valor da produção dos produtos das lavouras temporárias, segundo a Unidade da Federação, suas Mesorregiões, Microrregiões e Municípios, CEARÁ, 2018. Disponível em: $<$ https://sidra.ibge.gov.br/geratabela?name=Tabela\%203.6\%20\%20Ceara.xlsx \&format=xlsx\&medidas=true \&qu ery=t/1612/g/19/v/allxp/p/2015/c81/all/1/p\%2Bc81,v,t $>$. Acessado em: 20 de jun. 2019.

KARDEC, A.; NASCIF J. Manutenção: função estratégica. $3^{a}$ edição. Rio de Janeiro: Qualitymark: Petrobrás, 2009. $384 \mathrm{p}$.

MARQUES, Alessandro Pereira. Planejamento e programação na base: estudo de caso Petrobras UO/Rio. In: ENCONTRO NACIONAL DE ENGENHARIA DE PRODUÇÃO, 34., 2014, Curitiba. Anais Eletrônicos... Curitiba: ABEPRO, 2014

SLACK, Nigel; CHAMBERS, Sturart; JOHNSTON, Robert. Administração da Produção. 8. ed. São Paulo: Editora Atlas, 2018. 728 p.

VIANA, Herbert R. G. PCM - Planejamento e Controle da Manutenção. 1ª Edição, Qualitymark Editora. Rio de Janeiro - RJ, 2014.

XENOS, Harilaus Georgius. Gerenciando a manutenção produtiva. 2. ed. Nova Lima-MG; Editora Falconi, 2014. $312 \mathrm{p}$.

ZARREH, Alireza; WAN, HungDa; LEEA, Yooneun; SAYGINA, Can; JANAHIA, Rafid Al. Cybersecurity

Concerns for Total Productive Maintenance in Smart Manufacturing Systems. Procedia Manufacturing. v. 38, p. 532-539. 2019. $29^{\mathrm{a}}$ Conferência Internacional sobre Automação Flexível e Manufatura Inteligente

(FAIM2019). Limerick, Irlanda. 24-28 de junho de 2019. 